\title{
REFLEXIONES ÉTICO-POLÍTICAS PARA EL ABORDAJE DE USO PERJUDICIAL DE DROGAS: HACIA LA PRODUCCIÓN DE VIDA Y LA AMPLIACIÓN DE LOS DERECHOS HUMANOS*
}

Juan Pablo Burwiel

\section{Introdução}

Los derechos humanos nacen ante la necesidad de configurar un sistema universal de protección de las vidas de las personas. Diversos episodios que acontecieran en la humanidad demuestran que la violencia persiste, que la vida puede ser arbitrariamente arrebatada o controlada por factores de poder o desigualdad. Los usuarios de drogas no son ajenos a esta realidad donde las injusticias prevalecen. Las prácticas de encierro, criminalización del uso de drogas, procesos pauperización, discriminación y todo tipo de violencias son situaciones que viven su vida cotidiana.

En lo que respecta al ámbito de la salud, consideramos que varios de los padecimientos y las demandas de cuidado presentadas por los usuarios están estrictamente ligadas a la vulneración de sus derechos. Con esto queremos decir que la producción de salud, en muchos casos, se vincula a garantizar y reparar derechos. En el caso de la población que asistimos, varios de sus padecimientos no tienen que ver inmediatamente con el uso problemático de drogas, sino que éste se vincula al sufrimiento social que produce los efectos de la exclusión social. Así, la salud pública se involucra en el tratamiento de las manifestaciones somáticas que emergen del sufrimiento producido por la vulneración de los derechos humanos. Es menester, por lo tanto, problematizar sobre el rol de la salud pública en generar dispositivos de atención que se centren en la protección de los derechos humanos.

*DOI- 10.29388/978-65-86678-44-4-0-f.139-160 
El objetivo de este texto consiste retomar la experiencia de la lucha por los Derechos Humanos en Argentina y la bibliografía de la Salud Colectiva para hacer una propuesta de intervención que se centre en la ampliación de derechos y en la producción de dignidad para los usuarios de drogas. Por otro lado, se harán mención de aquellos basamentos ético-políticos que posicionan al Trabajo Social y a la intervención social como agente indispensable en la producción de actos de salud.

\section{Prácticas de exclusión, expulsión y vulneración de dere- chos en los usuarios de drogas.}

Antes de comenzar con algunas ideas, resulta importante trazar la relación entre cuerpo y política de modo que podamos aproximarnos a la noción de que algunas prácticas de vulneración de derechos se relacionan al tipo de gestión de salud y de los cuerpos. Sobre esto podemos citar a una reciente referencia de Paul Preciado (2020) donde dice:

Lo más importante que aprendimos de Foucault es que el cuerpo vivo (y por tanto mortal) es el objeto central de toda política. II n'y a pas de politique qui ne soit pas une politique des corps (no hay política que no sea una política de los cuerpos). Pero el cuerpo no es para Foucault un organismo biológico dado sobre que después actúa el poder. La tarea misma de la acción política es fabricar un cuerpo ${ }^{1}$.

Por otro lado, Giorgio Agamben (2017) también se refiere a la politicidad del cuerpo, aludiendo que:

Al final de La Voluntad de Saber, como vimos, el proceso a través del cual, en los umbrales de la época moderna, la vida se vuelve la apuesta de la política, se resume en una fórmula ejemplar: "Por milenios el hombre siguió siendo lo que era para Aristóteles: un animal viviente y, además, capaz de existencia política; el hombre moderno es un animal en cuya política está en cuestión su vida de ser viviente" (AGAMBEN, 2017, p. 181).

\footnotetext{
${ }^{1}$ Disponible en: < https://www.lavaca.org/notas/encerrar-y-vigilar-paul-preciado-y-la-gestion-de-las-epidemias-como-un-reflejo-de-la-soberania-politica/>. Consultado en: 10 set. 2020.
} 
Los autores de referencia recuperan de la obra de Foucault para trazar la relación entre salud y la política que confluye en lo que ellos Ilaman biopolítica. En relación a esto Patricia Digilio (2010), docente de la Universidad de Buenos Aires, nos trasmite que el objetivo de la biopolítica es establecer mecanismos globales de regulación de los fenómenos propios de la vida. Desde esos mecanismos de regulación se producen efectos que permiten identificar en la población lo sano y lo enfermo, lo normal y lo anormal, lo productivo y lo improductivo y a partir de esta identificación llevar adelante acciones "de separación, marcación, exclusión y a partir de esto desplegar esos mecanismos político-sociales de control o disciplinamento" (DIGILIO, 2010).

A esto agrega que categorías como "patología, higiene y salud" son abordadas por disciplinas específicas que, además de sus prácticas profesionales, diseñan formas de intervención que impactan funcionamiento del cuerpo social. El trasfondo político de la gestión de la salud, o de lo que en una época dada emerge como "enfermedad", produce así la relación, no metafórica, sino concreta y real de la política con la biología/medicina (DIGILIO, 2010).

Desde lo expuesto, entonces, me pregunto cómo es la relación concreta entre salud y política específicamente en la temática de las drogas. Para esto podemos iniciar diciendo que en el modo en que una sociedad trata a sus pacientes encontramos algo de su ética, un reflejo de sus valores y el tipo de políticas de inclusión y empatía al padecimiento que ésta promueve. En la problemática del uso perjudicial de sustancias no sólo encontramos un tipo de gestión en salud, sino también un tipo de accionar ético-político que atraviesa inherentemente a los derechos humanos

El primer punto a considerar sobre la temática en relación a los derechos humanos tiene que ver con qué lugar se les asigna a los usuarios de drogas en su comunidad. La pregunta por el lugar es significativa ya que la gestión de los cuerpos supone siempre un tipo de espacialización de lo que se construye como enfermo o patológico. En el libro "Foucault y lo político", se hace mención al modo en que la política administraba que lepra y la locura, diciendo que en cada época histórica existe una voluntad de verdad que delinea el topos (lugar) donde se ubican las palabras y las cosas. Es esa misma voluntad 
la que organiza el topos de la enfermedad y el logos (discurso) que la nombra, que la visibiliza o la invisibiliza. "También la territorializa, al tiempo que la excluye, que la espacializa en un espacio determinado con el objetivo de aislarla, para evitar contaminaciones indeseables o mezclas que atenten contra la utopía higiénica de una comunidad pura" (COLOMBANI, 2009, p. 45).

Si para la lepra el lugar asignado era el leprosario, para la locura el manicomio, para los usuarios de drogas el lugar es la comunidad terapéutica, la cárcel o la situación de calle. El tipo de gestión que fomenta la sociedad actual para los usuarios de drogas es la expulsión social. No es la droga en sí lo que provoca el debilitamiento de los lazos sociales, sino la administración misma de la problemática que expulsa a los usuarios del sistema. Vale aclarar que la expulsión social, no es un concepto más en el tema a exponer, sino que expresa una serie de particularidad que a continuación se detallan. Algo de la hondura del concepto la encontramos en la distinción entre expulsión y exclusión, definida de la siguiente manera:

La exclusión pone el acento en un estado: estar por fuera del orden social. La idea de expulsión social, en cambio, refiere la relación entre ese estado de exclusión y lo que o hizo posible. Mientras el excluido es meramente un producto, un dato, un resultado de la imposibilidad de integración, el expulsado es resultado de una operación social. (...) La expulsión social produce un des-existente, un "desaparecido" de los escenarios públicos y de intercambio. El expulsado perdió visibilidad, nombre y palabra; es una "nuda vida" (...) porque han entrado en el universo de la indiferencia, porque transitan por una sociedad que parece no esperar nada de ellos (DUSCHATZKY; COREA, 2009, 18).

Esta última cita nos ayuda a pensar que en el modo de arbitran los espacios sociales no hay sólo la asignación de lugar para determinado sector social, sino que a esto subyacen una cadena de operaciones sociales de fuerte impacto en la subjetividad. Retomando lo anterior, la topología del expulsado, no sólo explica condiciones espaciales, sino que esa esa topología está tal vez el principio de la violencia misma: a quienes se le asigna un lugar por fuera de su cultura es a quienes se los somete a la violencia arbitraria ya que es un modo de producir ignominia y descalificación en determinados sectores. Se 
puede pensar, entonces, que en toda práctica de expulsión hay un tipo de la violencia que la funda, la supone, la explica y le va a continuar.

Los derechos de primera generación no protegen al ser humano en cuanto tal, sino, a aquellos sujetos que se encuentren cobijados bajo alguna categoría jurídica que los integre en una comunidad política, como es la categoría de ciudadano. Esto avala la hipótesis de que existen prácticas sociales que producen investimentos positivos o negativos de sentidos hacia las personas. Esto origina tipos desiguales de cuidados o protecciones para los cuerpos. De estas formas diferenciales de abordar la abordar la vulnerabilidad humana deviene la noción de precariedad que destaca Judith Butler.

Frente a la común condición ontológica de vulnerabilidad, Butler opone una noción más específicamente política de "precaridad", con la cual designa "esa condición políticamente inducida en la que ciertas poblaciones adolecen de falta de redes de apoyo sociales y económicas y están diferencialmente más expuestas a los daños, la violencia y la muerte" (BUTLER, 2010; 2009b apud MATTIO, 2010, p. 167).

En este sentido, los derechos humanos vienen a proponer, como alternativa, un tipo universal de humanidad que no produzca segregaciones o exclusiones a la hora de velar por el cuidado de las personas. Esto viene a marcar una diferencia con la "Declaración Universal de los Derechos del Hombre y del Ciudadano", que suponían un tipo específico de humanidad y era el Estado-Nación quien otorgaba la calificación fundamental, desde la categoría de ciudadano, en el proceso de subjetivación. Esto lo explica Agamben (2017) en el capítulo "Los derechos de hombre y la biopolítica" cuando problematiza sobre los "refugiados y apátridas" al decir que les restringía el acceso a sus plenos derechos, situación que los exponía a la violencia y a la muerte; quien no ingresaba a la condición de ciudadano, como el loco o el extranjero sufría la pérdida de sus derechos básicos.

En los tiempos que corren, las prácticas totalitarias no requieren necesariamente de la reclusión o el encierro, sino que la violencia se gesta en alianza estrecha con la expulsión social, donde sobre esa población calificada como sobrante se practican todo tipo de arbitrariedades. "Por eso la Declaración Universal de los Derechos Humanos 
impone a los Estados parte el deber de respetar los derechos y libertades (...) a toda persona sin discriminación alguna y por si quedaran dudas, en su segundo apartado del artículo define persona como todo ser humano" (GUALDE, 2010, p. 68-69).

Bajo esta perspectiva, podríamos llegar a pensar que desde la Declaración Universal De los Humanos tendríamos el problema de la inclusión y la protección de las personas resuelto. Sin embargo, la sociedad no sólo produce vulneraciones en un sentido estrictamente formal, sino que la condición de precariedad tiene un histórico, político y económico. El mercado, en tiempos neoliberales es la nueva variable que determina los procesos de subjetivación, de modo que impacta de lleno en las condiciones de inclusión-exclusión. Si bien, los Derechos Humanos superan la aporía de la ciudadanía, ya no es el Estado el principal articulador del lazo social hoy en día. El mercado desde un capitalismo neoliberal viene a proponer nuevas formas de producción de subjetividades. Desde esta perspectiva, se corre el riesgo de que comiencen a haber nuevas formas de precariedad de la vida arbitradas por el mercado, lo que lleva a reflexionar sobre los nuevos desafíos para los que militamos los derechos humanos.

Según el autor, Ignacio Lewkowicz (2012), la práctica del consumo es que organiza los procesos de subjetivación y articulación del lazo social en tiempos neoliberales. La expulsión que antes describimos, no es un accidente histórico ni un tipo cualquiera de tramitación de la cuestión social. La expulsión es la operatoria misma de la sociedad de consumo y del mercado. Para el autor, la modalidad específica de exclusión, en nuestra época, no es la reclusión sino la expulsión, que la define como un movimiento hacia las zonas excluidas de la humanidad, "hacia una tierra no simbólica por fuera de la humanidad instituida" (LEWKOWICZ, 2012).

También agrega que esta operación es efectiva desde el momento que los actos de consumo pueden ampliarse en pocas personas y éstos no requieren de toda la población para multiplicarse. Sugiere que basta con que se multipliquen los actos de consumo de cada consumidor para que esta multiplicación sustituya al número de expulsados que ya no acceden a mercado. El problema de esto es que quien quede por fuera este modelo a la larga deja de ser considerado 
persona, porque la práctica instituyente de la subjetividad es el consumo (LEWKOWICZ, 2012).

Si el modo de exclusión de la locura era la reclusión, el modo de exclusión de los no consumidores es la expulsión. Del sitio de reclusión no se puede salir; los expulsados de la red no pueden entrar. (...) El carácter tajante de la demarcatoria determina limpiamente la imposibilidad de irrupción intempestiva de los expulsados en el mundo de la red (...) Los locos ya no se someten a la lógica de la reclusión, sino que quedan entregados a un mundo privatizado, a un mundo de locuras privadas. Quedan entregados a una dinámica que habrá que llamar de expulsión y aniquilación o transformación en nada (...) Se confía la locura a las capacidades de expulsión y aniquilación del consumo y la imagen (LEWKOWICZ, 2012, p. 80).

En este mismo sentido es Patricia Digilio (2010) quien nos advierte de los efectos biopolíticos de la exclusión social. Ella refiere que,

[...] afirmar la común dignidad de los seres humanos es la condición para reconocernos como iguales, iguales en nuestras diferencias. Pero si en este proceso, la alteridad se vuelve radical no conduce sino a la deshumanización del Otro, ya sea en la forma de exclusión, la asimilación o el exterminio. Finalmente señala que "la sombra que proyecta la biopolítica es la de la tanatopolítica y la línea que separa a una de otra es tan difusa como débil (DIGILIO, 2010, 55-56).

Desde lo que plantean los autores se puede ser una reflexión sobre el rol que tiene el discurso higienista en la producción de esa alteridad radical. Como veremos más adelante el padecimiento relacionado al uso perjudicial de drogas no es ajeno a la sociedad del consumo y al modelo neoliberal. La relación entre política y medicina se vuelve concreta en el momento en que los excluidos del sistema son capturados desde el discurso patológico. Si el encadenamiento de complejidades que se presentan en el padecimiento relacionado al uso perjudicial de drogas lo reducimos a noción de "enfermedad" o "adicción", estamos más cerca de una operatoria que busca segregar para vulnerar que de alojar para cuidar.

Por eso digo que en la misma exclusión existe el fundamento del padecimiento, o, dicho de otro modo, no es que la droga lo que 
"enferma" sino que es la expulsión la que produce los efectos mórbidos. En este sentido, encontramos la premisa ética de la inclusión, no sólo por hecho garantizar los derechos básicos de cualquier persona, sino que en las prácticas de integración social y cuidado existe una forma de producir salud en el padecimiento que traen los usuarios. Este tipo de nuevos padecimientos que conmueven los dispositivos tradicionales de atención tienen que ser objeto de reflexión para poder proponer estrategias para los nuevos emergentes desde una perspectiva de derechos, ya que éstos deben estar a la altura de los desafíos de la época.

\begin{abstract}
Ahora bien, junto a los derechos humanos consagrados, existen los derechos humanos emergentes. Se trata de aspiraciones a espacios de libertad que aún no han sido reconocidas por la norma positiva. El ejemplo que se suele dar son los derechos de las diversas minorías o de sectores postergados de una sociedad y el camino histórico hacia su reconocimiento pleno en el orden jurídico e institucional (MATTAROLLO, 2010, p. 76).
\end{abstract}

En este modo de producir salud desde experiencias vinculadas a la promoción del lazo social, se encuentra un vínculo entre la estrategia de reducción de daños y la promoción de los derechos humanos. En cambio, el abstencionismo es el modelo que, en tanto práctica moralizante, funciona como dispositivo que subjetiva a los usuarios como culpables de su condición, privándolos de cuidado, y que al tiempo de criminalizar el uso de drogas construye un tipo de sujeto susceptible de ser encerrado o castigado. Inversamente, la estrategia de reducción de daños (RD) parte de la premisa de incluir al usuario en un itinerario de atención y cuidado sin juzgar o sancionar. De este modo, la pregunta por la inclusión tiene un peso significativo en los derechos humanos ya que estos se vulneraron de forma cruel y sistemática cuando se produce un tipo de sujeto desafiliado, que se lo descalifica como persona y se le restringen los factores de protección.

La exclusión ubica a los usuarios por fuera de la ley, situación que tiene un impacto subjetivo determinante. Esta exclusión inducida avala un tipo de humanidad desprestigiada que permite que los derechos se vulneren sin que esto sea cuestionado. Bajo este aspecto, los 
derechos humanos son una respuesta ética a la cuestión del lazo, desde el momento que universalizan lo humano, disputan esa moral fragmentada y velan por la integridad de todas las personas. No existe vida que ni por motivos de clase, etnia, salud o género pueda ser menos valorada, cuidada o protegida que otras. Jamás, entonces, que sea arbitrariamente arrebatada.

\section{Del sujeto de la consciencia al sujeto ético.}

A partir de las consideraciones expuestas, se considera que el fenómeno de captura de los emergentes subjetivos de época por discurso que lo reduce a la mera condición patológica produce una degradación en la condición humana. Por eso me parece importante situar las categorías de padecimiento y subjetividad (en lugar de enfermedad) para poder pensar los horizontes ético-político de la intervención.

En este caso, la apuesta por la inclusión de los usuarios no se relaciona sólo con su reconocimiento de la persona, sino de ampliarlo al modo en que esa persona desenvuelve el mundo, en tolerancia con sus dificultades, conflictos, limitaciones o padecimientos. De esto se trata, al fin de cuentas nuestro rol como trabajadores de salud: producir alivios y cuidados en el sufrimiento. Para esto, introducimos la pregunta por la regulación del uso de drogas, como estrategia de cuidado y de intervención clínica en su uso perjudicial. Edith Benedetti (2015) plantea que es fundamental dar lugar a la toma de decisiones, incorporando medidas que permitan el uso controlado de sustancias. Para esto la noción de "regulación del consumo" es un punto crucial en su propuesta de intervención ya que supone un movimiento en la posición subjetiva del paciente concomitante en un efecto clínico (BENEDETTI, 2015). La meta de este apartado, será retomar la idea de regulación desde la propuesta de "construcción de legalidades".

Por otro lado, el tipo de tratamiento que se le da a las presentaciones clínicas emergentes de una época refleja los fundamentos éticos de dicha sociedad: si opta por recluirla de la comunidad o la aloja dentro de sí con sus respectivos valores y derechos. La temática de uso de drogas nos invita a reflexionar al respecto. Lewkowicz 
(2012) analiza esto diciendo que las patologías con las que la modernidad nos enseñó a lidiar se deslocalizaron y ubica nuevas formas de sufrimiento como "las adicciones, anorexias y bulimias" que suelen nombrarse bajo el rótulo de la" clínica del borde".

Si el síntoma del sujeto de la conciencia se constituyó como sujeto del inconsciente, si la histeria constituyó la superficie de emergencia de ese sujeto del inconsciente, ¿̇por qué no suponer que la anorexia y las adicciones constituyen otras tantas superficies de emergencia de eso que hace síntoma en lo que la dinámica actual instituye como sujeto? A partir de ahí, podemos leer que estas patologías de borde, estas anorexias, bulimias, adicciones, se presentan como patologías del consumo y como patologías de la imagen (LEWKOWICZ, 2012, p. 114).

Lo que la sociedad viene a nombrar, entonces, como "adicción" son una serie de fenómenos heterogéneos que responden a distintos tipos de padecimientos y diversas respuestas de alivio según lo que atraviesa el sujeto. Por lo tanto, no puede leerse como una mera patología, sino desde los nuevos fenómenos que surgen de la emergencia de nuevas subjetividades. Silvia Bleichmar (2006) se pregunta con qué tipo de teorías contamos para enfrentar los nuevos fenómenos clínicos, y que no se trata de hablar solamente de nuevas patologías sino de tener en cuenta las nuevas formas del destino del deseo o, mejor dicho, que la patología es una última instancia el efecto de una relación entre inconsciente y las posibilidades que le da una época histórica a la resolución de las tensiones del deseo (BLEICHMAR, 2006).

En función de esto, Lewkowicz (2012) prefiere no hablar de patología o enfermedad, sino que indica que el concepto de "adicción" responde a una figura socialmente instituida, es un tipo subjetivo que se desprende de la subjetividad del consumidor. El consumidor está producido por una serie de prácticas específicas. Esta serie de prácticas lo instituye como un sujeto que varía sistemáticamente de objeto de consumo sin alterar su posición subjetiva. El autor también distingue entre "adicción" y "drogodependencia" ya que "la subjetividad adictiva" no depende necesariamente de las drogas. A esto agrega, que las drogas en sí no producen adicción, que las drogas existen 
mucho tiempo antes de que emerja la categoría sanitaria de "adicción" y que existen usos perjudiciales que relacionan a casi cualquier objeto de la cultura.

Con lo cual la "adicción" es una representación que ideologiza un tipo subjetivo que sólo tiene dos destinos posibles: ser adicto o no. $Y$ bajo esa dicotomía se trazan una serie de operaciones políticas que potencian su vulnerabilidad. El que no puede torcer el destino de "ser adicto" por el simple hecho de usar drogas, sólo puede asumir como posibilidad la internación, la cárcel o la culpa de merecer sus desdichas. No me extrañaría que bajo esa lógica algunas personas prefieran continuar usando drogas abusivamente. En este sentido lo insano no es la droga, sino ese destino social cargado de impotencia, exclusión y sufrimiento.

La problemática de los usos perjudiciales o usos no regulados de drogas no tenía peso en la salud pública que tiene hoy en día. La figura del "adicto" es posible en situaciones en que el soporte subjetivo del Estado ha dejado de ser el ciudadano, que resulta del principio revolucionario de igualdad ante la ley, y ha recaído en la figura del consumidor. La figura de sujeto del consumidor por otro lado desplaza el lazo social que constituye a la ciudadanía hacia un tipo de lazo social que se apoya en la identificación del sujeto con el objeto (LEWKOWICZ, 1999).

El desmantelamiento del Estado, como protagonista de la política pública, como articulador de lazo social y como soporte de subjetividad nos invita a pensar sobre nuevas formas de pensar el lazo, y que ficciones o ideologías van a articular a los sujetos con valores comunes. El neoliberalismo no propone una salida a este problema, sino que lo acrecienta. Muchas de las situaciones que enfrentamos hoy en día tienen que ver con las formas perversas en que la desigualdad social estructura el lazo y las subjetividades. Al mismo tiempo, el mercado hoy en día induce a las personas a desentenderse los límites que pauta el semejante, a relacionarse desde el exceso y el egoísmo de la competencia.

La técnica de poder del régimen neoliberal no es prohibitoria, protectora o represiva, sino prospectiva, permisiva y proyectiva. El consumo no se reprime, se maximiza. No se genera escasez, sino abundancia, 
incluso exceso de positividad. Se nos anima a comunicar y a consumir. El principio de negatividad, que es constitutivo del Estado vigilante de Orwell, cede ante el principio de la positividad. No se reprimen las necesidades, se las estimula (HAN, 2014, p. 33).

Sin embargo, esto no puede leerse como una derrota, sino como un conflicto que nos lleve a reflexionar sobre nuevas formas de lazo social, nuevos modos de anudamiento comunitario, y diversas prácticas que capturen los fenómenos sociales y subjetivos de nuestra época de un modo creativo. No se trata de conformarnos con el sujeto neoliberal como alternativa a la sociedad disciplinar, ni tampoco de intentar volver a ella por efectos nocivos de la praxis consumista. El problema de la regulación no tiene que ver con producir elementos prohibitivos o represivos en sí, sino con reflexionar sobre formas en que los sujetos ceden algo de sí mismos para abrirse a las posibilidades de sus semejantes. Por eso, existe una confusión cuando se vincula la práctica de consumo neoliberal solamente a la relación con las cosas. Las prácticas desregulantes de sociedad neoliberal tienen su impacto más negativo en el vínculo entre sus miembros. A decir sobre esto, Lewkowicz refiere:

El consumidor es un ente atómico desvinculado de otros. El mercado produce desvinculación. Si la familia era la célula básica de la sociedad, el consumidor no es célula de nada. Es él, en su mundo. Para hablar honestamente, soy yo en mi mundo. Pero una cosa es producir locura por dispositivos de normalización y otra es producir locura por dispositivos de atomización. Es otra locura (LEWKOWICZ, 2012, p. 109).

La propuesta para pensar nuevas legalidades y regulaciones en nuestro tiempo, proviene de Bleichmar (2006). Ella formula la noción de "sujeto ético", que nos sirve para hacer un contrapunto con el "sujeto de la consciencia" y proponerlo como alternativa al "sujeto de la imagen". Así como la ciudadanía toma la conciencia y la razón como valor estructurante del ser social (de ahí que se excluía primordialmente a la locura), el sujeto de la imagen toma al consumo como práctica constitutiva. En contraste, la empatía y el afecto es el rasgo significativo del sujeto ético. 
Para la autora, la ética está basada en el principio del semejante, la ética está basada en la forma a que uno enfrenta sus responsabilidades hacia el otro, la ética es la presencia del otro (BLEICH$M A R, 2006)$. El sentido de promover un sujeto ético tiene por objetivo sembrar una responsabilidad colectiva que mane de sentir y percibir el sufrimiento del semejante. En una línea parecida, Leonardo Boff propone una ética basada en el "pathos", o sea la capacidad de sentir en profundidad al otro, ya que la ética, en sí misma, surge y se renueva siempre que el otro emerge frente a nosotros (BOFF, 2012).

Bleichmar, en una conferencia dictada en el año $2006^{2}$, relata que en el abordaje de personas en situación de vulnerabilidad es fundamental rastrear la existencia de enlaces libidinales que propicien la posibilidad de un rescate de la autodestrucción o de la destrucción del otro ya que el sujeto sólo puede amar la ley cuando esta emana de un objeto amado. A esto agrega, que este tipo de ley, que emana de un objeto amado opera más allá de las normas del sistema a las que el sujeto odió desde un comienzo porqué sintió que solo lo excluían o lo dañaban. "De manera que el problema consiste en ver quienes siguen conservando potencialidad amorosa y la capacidad no sólo de amar al otro sino a aquello que el otro propone" (BLEICHMAR 2011, p. 185). Este sería principio fundamental para la inscripción de una legalidad en un sujeto.

En la construcción de un sujeto ético, toma relevancia la producción y promoción de lazos social al punto que la persona pueda sentirse reconocida y cuidada conformando un punto inflexión a la hora de subjetivarse. "La ley en términos de auto conservación no alcanza para constituir un sujeto ético. La única garantía del sujeto ético reside en que la ley sea acorde al amor y respeto que se le tiene a quien la trasmite" (BLEICHMAR 2011, p. 186). A diferencia de esto, señala que la moral pragmática basada en el castigo o el miedo, no construye legalidades, ya que cuando la pauta se ejerce de forma efectiva, hay una creencia en el otro que se funda el amor y no en el miedo (BLEICHMAR, 2006).

Sin embargo, la autora plantea que es muy difícil trabajar en este tipo de ética sí que es todavía persisten prácticas de impunidad

${ }^{2}$ Conferencia disponible en: <https://www.youtube.com/watch?v=WrlvHULv5GQ>. Consultado en: 12 set. 2020 
en otros niveles y si se perpetúan injusticias a nivel público y comunitario. Por eso, para que las obligaciones éticas se constituyan respecto al otro, tengo que tener una noción de semejante que sea abarcativa. Para esto cita el ejemplo del jefe de un campo de concentración podía sentir culpa de no pasar la navidad con sus hijos, pero no de mandar a matar 200 niños. Esta persona definía el concepto de semejante respecto a los propios y no a los ajenos. Desde este punto, evitar construir arquetipos subjetivos que estigmatizan o degradan la condición humana es otro elemento imprescindible para la construcción de una nueva ética. La inclusión con práctica constante y transversal a toda intervención en salud es ineludible ya que una de las formas primeras de ejercer la impunidad es la invisibilización de la víctima porque deja de ser visible, esto es lo que ha pasado con los excluidos (BLEICHMAR, 2006).

Por lo tanto, si pensamos en el abordaje de presentaciones clínicas "del borde" (las que dislocan algo de lo esperado o lo moralmente correcto) decimos que la clave no está en la puesta de límites sino en la construcción o producción de legalidades. De ahí la importancia de avanzar hacia un sujeto ético, que se propone superar los dispositivos tradicionales de disciplinamiento del sujeto de la consciencia. "No hay posibilidad de constituir ningún tipo de normativa sino sobre la base de investimentos amorosos sobre el semejante" (BLEICHMAR, 2011, p. 110).

Posteriormente, Leonardo Boff (2012) nos trae la idea de una "razón cordial", que hace énfasis en la capacidad de afectar y ser afectado, que también nos sirve para pensar que tipo de sujeto contemporáneo construimos y hacia a donde pensamos las intervenciones psicosociales. Boff hace un aporte interesante al respecto, diciendo que "una ética que parte de la absoluta autonomía del sujeto en la soledad de su libertad es una irrealidad y una ilusión. A esto contrapone una ética del cuidado es otra donde el sujeto esta siempre ligado y religado, envuelto en una trama de conexiones" (BOFF, 2012, p. 78).

En este sentido, la abstención de sustancias opera como norma moral del problema, que puede tener la utilidad parcial de conservar al sujeto de una situación aguda o de algún efecto negativo, pero no avanza a fondo sobre la construcción de nuevas legalidades. 
Entendidas éstas como principios colectivos, proyectos de personales anudados a los comunitarios. Legalidades que operan como dique del subjetivo, que no reprimen, sino que enlazan algo del deseo propio con al deseo de los otros, sobre los cuales el usuario se apoyará.

\section{Derechos Humanos y estrategia de reducción de daños: dos paradigmas imprescindibles para los tiempos que cor- ren.}

Cuando hablamos de pensar un sujeto de derechos desde la perspectiva los derechos humanos, aludimos a se reconozcan todos los tipos de derechos: civiles, políticos, económicos, sociales, culturales etc. Esto, a la hora de suponer un tipo de subjetividad, no alcanza en pensar una ética sólo desde la razón, un sujeto capaz de asumir su responsabilidad ante la ley de su comunidad. Sino, como platea Leonardo Boff (2012), es necesario una ética basada en el "pathos", esa forma de percibir la realidad desde a ternura y cuidado por los otros. Es de suma relevancia recalcar los efectos positivos, efectivos y saludables de quienes como trabajadores de la salud practicamos la ternura y la hospitalidad como método para la construcción de legalidades en presentaciones complejas.

Silvia Bleichmar (2011) también nos enseña, no sólo que a inscripción de la ley no se gesta por miedo a castigo, sino que ésta es efecto de a renuncia a goce propia por amor al otro. Por eso, la construcción de nuevas legalidades tiene como fin primordial fortalecer el lazo social desde la ética ya referida. Al mismo tiempo, esto puede servir como una herramienta para hacerle frente al individualismo neoliberal su que fomenta la competencia, la indiferencia y apatía sobre el otro.

En este sentido, observamos que aún en el marco formal de la igualdad ante la Ley, el Estado moderno no ha podido alojar de forma plena a todos los ciudadanos y las subjetividades emergentes. En el caso de los usuarios de drogas, no sólo fueron injustamente criminalizados, sino que también fueron patologizados los efectos de esa exclusión y expulsión. A partir de la revisión de estas ideas, es que la sociedad ha podido pensar alternativas novedosas y actuales para el 
cuidado de todas las corporalidades: se ha avanzado en políticas de género y disidencias, infancias o las personas con discapacidad.

Para la población usuaria de drogas, la estrategia de reducción de riesgos y daños (RD) es la que permite introducir la perspectiva de los derechos humanos en esta población tan maltratada. Para ofrecer una propuesta de intervención desde estos dos grandes paradigmas, se va a ordenar el análisis en tres momentos: (1) reconocimiento, (2) reparación y (3) cuidado-emancipación.

(1) El reconocimiento supone la inclusión de un sujeto excluido por su comunidad. El usuario de drogas fue arbitrariamente estigmatizado, al mismo tiempo que despojado de racionalidad y de capacidades de decidir. Se dice que puede muy poco por sí mismo y que las cosas que hace o piensa son efecto de las drogas. Hegemónicamente se lo representa como un sujeto despojado de conciencia, situación que habilita la vulneración de sus derechos básicos. La reducción de daños (RD) reconoce un sujeto capaz de decidir por sí mismo y responsabilizarse de sus actos, incluso en el seno mismo del uso de drogas. No implica, ni debe, el uso de drogas significar que algún derecho pueda ser suspendido.

La reducción de daños (RD), desde el momento que reconoce a la persona (independientemente si usa drogas o no), permite un abordaje clínico basada en el vínculo y la confianza que se gesta con el usuario. El eje supone un acto de salud en la medida en que produce las condiciones mismas para la intervención. La inclusión, como acto de no criminalizar o no inducir el encierro, es el evento primordial para que el usuario reconozca a un Otro como posible articulador de cuidados. Es una práctica basada en los derechos humanos porque reinscribe a la persona en la humanidad políticamente reconocida y amplia el concepto de semejante para determinado grupo o comunidad.

Luego, la (2) reparación tiene que ver con investir de sentidos a esa persona, inscribir en el usuario la idea de que su comunidad le da está dando un lugar y que sobre eso pueda pensar algún tipo deseo. El usuario ya inscripto en un lazo posible, con un trabajador o un dispositivo de salud, puede empieza a desplegar o relatar las vulneraciones sufridas como falta de oportunidades, violencias, estigmatización en su entorno familiar o situaciones de pauperización. La inter- 
vención consiste en comenzar a reparar esos derechos vulnerados en la medida que usuario lo vaya deseando. Hacer ofertas de reparación desde apoyos económicos, inserción en propuestas ocupacionales, ampliación de la red sostén o entrevistas con referentes afectivos admiten una serie de cuidados que elevan la calidad de vida de la persona.

A diferencia de los modelos conservadores que asocian la calidad de vida al sostén abstinencia y que las prácticas asociadas a trabajar sobre un proyecto de vida recién comienzan una vez que la persona deja de consumir; los actos de salud que se vinculan a la intensificación de cuidados empiezan en el mismo momento en que se gesta en vínculo terapéutico, nunca dependiente de la manera en que la persona hace uso de las drogas. Es un paso que permite imaginar un futuro que se interponga a la inmediatez del consumo como fenómeno de la exclusión neoliberal. En este sentido se comienza a situar en detalle los cuidados necesarios para que esa persona se recomponga de los efectos perjudícales del uso de drogas, ya no solo en el alojamiento, sino desde la producción efectiva de nuevas oportunidades.

En resumen, la adopción de la perspectiva de reducción de daños (RD) presupone una apertura para el diálogo, reflexión, cuestionamiento y evaluación continua de las intervenciones. El enfoque basado en la reducción de daños implican tener en cuenta la vulnerabilidad de las personas. La noción de vulnerabilidad, entendida como el resultado de interacciones que determinar la mayor o menor capacidad de los sujetos para protegerse o someterse a riesgos, permite la singularización de las intervenciones y converge con las ideas ya presentadas (OLIVEIRA, 2007).

El tercer momento (3), cuidado-emancipación, consiste en la construcción de legalidades, estrechamente asociada a la constitución del sujeto ético. Al primer eje de reconocer al usuario sujeto pleno de derechos, se agrega el segundo ítem que consiste en intentar igualar a ese sujeto al resto de las oportunidades de su comunidad. El tercero, consiste en acompañar el modo en que esa persona restituye los sentidos y afectos que lo puedan vincular a un proyecto de vida significativo para él o ella. Es crucial para esto incorporar la noción de "producción de vida" que se en el texto "Clínica ampliada, equipo de referencia y proyecto terapéutico singular": 
Otro aspecto fundamental de la clínica ampliada, además de la búsqueda de autonomía para los usuarios, es la capacidad de equilibrar la lucha contra la enfermedad con la producción de vida y esta participación no puede entenderse como una dedicación exclusiva a la enfermedad, sino más bien como una capacidad de "inventarse" a pesar de la enfermedad. (...) Las intervenciones de salud mental deben promover nuevas posibilidades para modificar y calificar los modos de vida, guiados por la producción de vida y no restringido a curar enfermedades. Esto significa creer que la vida puede tomar muchas formas ser percibida, experimentada y vivida (BRASIL, 2007).

La problemática del uso perjudicial de drogas puede ser concomitante con un padecimiento subjetivo que puede ser aliviado produciendo factores protectores en los determinantes sociales que impactan en ese sufrimiento. La reducción de riesgos y daños (RD) por eso implica situar los usos perjudiciales y efectos negativos no en la droga misma, sino emplazados en los proyectos de vida significativos de las personas y trabajar con mayor precisión al respecto.

A diferencia de los dispositivos que disciplinan la subjetividad, de modo que el lazo social se gesta desde la modelización estructurada de ese sujeto, se piensa en dispositivos que involucren al usuario de forma empática con su entorno. No pensamos que cuestionar los dispositivos de la sociedad de disciplinamiento suponga una desregulación del lazo social, creemos en un tipo de ética que promueva el lazo social y la integración comunitaria, en el respeto de la libertad y la dignidad de la persona. Conjuntamente a esto, la promoción del lazo social desde una ética hospitalaria y desde un futuro colectivo con justicia habilita recursos subjetivos para que la persona construya nuevas legalidades en aquellos pasajes de su vida cotidiana que los requiera necesarios.

La vida es una permanente renuncia a goces inmediatos siempre y cuando se pueda proyectar algo a futuro. Una enorme cantidad de chicos en el país no tienen claro cuál es su futuro, o directamente no anhelan un futuro, viven en la inmediatez absoluta. Para revertir esto, es preciso tomar en cuenta la presencia del otro. El control tiene ver con una renuncia por amor a otro y no provocar sufrimiento en el otro. Es clave la definición del universo semejante. La crueldad 
no es solo la maldad ejercida sino la indiferencia ante el sufrimiento del otro (BLEICHMAR 2006) ${ }^{3}$.

A diferencia del modelo neoliberal que promueve un tipo de "libertad" basada en el goce auto-referencial, la libertad de individuo atomizado, apostamos al encuentro entre personas, con la complejidad que significa organizar una comunidad que vele y cuide por los derechos de todos sus miembros.

\section{Consideraciones finales}

Finalmente, la apuesta de ubicar el concepto de "cuidado" a la par a un concepto tan intenso como el de "emancipación", implica una revalorización del concepto de cuidado. En un principio, entendía al cuidado como un modo de garantizar las condiciones básicas de existencia, en un escalafón intermedio, como medio para alcanzar determinados fines en la vida social. En cambio, con el tiempo me percaté que el cuidado es el fin último de la comunidad, ya que ésta se emancipa en su conjunto. El cuidado como dimensión ontológica y antropológica muestra esta vinculación de todos basada en el hecho de una reciprocidad general. La ética de cuidado completa la ética de la justicia. Ellas no se oponen, sino que se "componen en la construcción de una convivencia humana fecunda, dinámica, siempre abierta a nuevas relaciones y cargada de sentimientos de solidaridad, afectividad, y en ultimo termino de amorosidade" (BOFF, 2012, p. 78).

No hay lazo social, ni regulaciones sociales, donde hay violencia social, desigualdad o necropolítica (MBEMBE, 2011). El neoliberalismo, no sólo nos desafía a revertir las injusticias y la precarización de la vida material y simbólica a la que nos arroja; sino que nos plantea hacer frente a un nuevo pacto social, un pacto que valorice la vida de los expulsados del sistema, un pacto que frene las violencias que éstos padecen y que transforme en prácticas comunitarias aquellas conductas que son capturadas desde el discurso higienista. No va a haber legalidades donde hay impunidad: es un absurdo pretender que los usuarios regulen el uso drogas mientras se los expulsa o que

${ }^{3}$ Disponible en: <https://www.youtube.com/watch?v=WrlvHULv5GQ>. Consultado en: 12 set. 2020. 
construyan un proyecto distinto de vida, mientras se los castiga. Por eso, insistir con una intervención ético-política basada en los derechos humanos amplía el espectro estratégico de los actos en salud calando con profundidad en aspectos centrales como la dignidad, la inclusión y el cuidado.

\section{Referências}

AGAMBEN, G. Homo sacer: el poder soberano y la nuda vida. Buenos Aires: Adriana Hidalgo Editora, 2017.

BENEDETTI, E. Hacia un pensamiento clínico acerca del consumo problemático. Buenos Aires: Ediciones Laura Bonaparte, 2015.

BLEICHMAR, S. La construcción del sujeto ético. Buenos Aires: Editorial Paidós, 2011.

. La construcción de legalidades como principio educativo.

Conferencia dictada el 29 de agosto de 2006. Disponible en:

<https://www.youtube.com/watch?v=WrIvHULv5GQ>. Consultado en: 12 set. 2020 .

BOFF, L. El cuidado necesario. Madrid: Editorial Trotta, 2012.

BRASIL. Ministério da Saúde. Secretaria de Atenção à Saúde. Núcleo Técnico da Política Nacional de Humanização. Clínica ampliada, equipe de referência e projeto terapêutico singular. 2 ed., série B., Textos Básicos de Saúde. Brasília: MS, 2007.

COLOMBANI, M. C. Foucault y lo político. Buenos Aires: Prometeo Editorial, 2009.

DIGILIO, P. Interferencias entre bioética, biopolítica y dignidad humana. En VVAA, La dignidad humana: Filosofía y Derechos Humanos. Buenos Aires: Colección Derechos Humanos para todos. Serie Debates y Nuevos Desafíos. Secretaría de Derechos Humanos. Ministerio de Justicia, Seguridad y Derechos Humanos, 2010.

DUSCHATZKY, S.; COREA, C. Chicos en banda: los caminos de la subjetividad en el declive de las instituciones. Buenos Aires: Editorial Paidós, 2009. 
GUALDE, A. Dignidad, derechos humanos y bioética. En VVAA, La dignidad humana: Filosofía y Derechos Humanos. Buenos Aires: Colección Derechos Humanos para todos. Serie Debates y Nuevos Desafíos. Secretaría de Derechos Humanos. Ministerio de Justicia, Seguridad y Derechos Humanos, 2010.

HAN, B-C. Psicopolítica: neoliberalismo y nuevas técnicas de poder. Barcelona: Herder Editorial, 2014.

LEWKOWICZ, I. Subjetividad adictiva: un tipo psicosocial instituído, condiciones históricas de posibilidad. En DOBON, J.; HURTADO, G. (Comps.). Las drogas en el siglo...¿¿qué viene? Buenos Aires: Ediciones FAC, 1999.

. Pensar sin Estado: la subjetividad en la era de la fluidez. Buenos Aires: Editorial Paidós, 2012.

MATTAROLLO, P. Ética y derechos humanos. En VVAA, La dignidad humana: Filosofía y Derechos Humanos. Buenos Aires: Colección Derechos Humanos para todos. Serie Debates y Nuevos Desafíos. Secretaría de Derechos Humanos. Ministerio de Justicia, Seguridad y Derechos Humanos, 2010.

MATTIO, E. Vulnerabilidad, normas de género y violencia estatal: ontologia social y política sexual en la última Judith Butler. Pensamento Plural, Pelotas, v. 07, p. 159-172, julho/dezembro, 2010.

MBEMBE, A. Necropolítica. Santa Cruz de Tenerife: Editorial Melusina, 2011.

OLIVEIRA, G. N. de. Projeto terapêutico como contribuição para a mudança das práticas de saúde. 203p. Dissertação (Mestrado em Saúde Coletiva) - Programa de Pós-Graduação em Saúde Coletiva, Faculdade de Ciências Médicas, Universidade Estadual de Campinas, Campinas, 2007.

PRECIADO, P. B. (2020) Encerrar y vigilar: Paul Preciado y la gestión de las epidemias como un reflejo de la soberanía política. Revista Mu - Universidad de Lavaca, Ciudad Autónoma de Buenos Aires, 29 de mar. de 2020. Disponible en: < https://www.lavaca.org/notas/encer- 
rar-y-vigilar-paul-preciado-y-la-gestion-de-las-epidemias-como-unreflejo-de-la-soberania-politica/>. Consultado en: 10 set. 2020. 